In addition to what has already been detailed, atropine is known in certain cases to cause slight general excitement, with increased frequency of the pulse; a bitter taste in the mouth; a peculiar form of conjunctivitis, where its use has been long contiuued; and not to be at all borne by certain individuals, who manifest a peculiar susceptibility to its influence.

The discovery of a mydriatic free from the above dangers and inconveniences, would mark a distinct advance in therapeutics, and facilitate examinations of the eye, whether of refruction or for purposes of exploration. Such an agent, it is claimed, hus been found in scopolamin, an alkaloid furuished by the roots of the scopolia atropoides. It is contained, with hyoscin, in the hyoscyamus niger or henbase, but differs materially from hyoscin in a chemical point of view.

A recent article published by Raehlmann (KI. Mo. natsbliztter für Augenheilkunde, Jahrg, XXXI, S. 59) drew attention to this new mydriatic. It is more active than atropine, being used in about one-fifth the strength of that agent, a solution of from one to two parts to a thousand being the one usually employed. It acts with efficiency, its first effect on tho pupil being in most of my cases visible at the end of five or six minutes, and full dilatation secured in from twenty to twenty-live minutes. Mydriasis lusts several days, but seems to be less prolonged than that due to atropine. Dr. H. H. Haskell, ophthalmic interne at the Massachusetts Charitable Eye and Ear Intirmary, has had the kindness to observe the results of the application of a one-fifth-per-cent. solution of scopolawin in a series of seven cuses, and the figures are here appended. The first column gives the age, the second the number of minutes that elapsed before any effect was perceptible, the third the minutes required for maximum dilatation, and the last the number of hours that elapsed before the pupil beçume again normal.

$\begin{array}{rrrr}9 & 8 & 40 & 61 \\ 8 & 16 & 35 & 60 \\ 17 & 10 & 21 & 72 \\ 12 & 9 & 30 & 80 \\ 9 & 10 & 26 & 60 \\ 20 & 10 & 20 & 80 \\ 12 & 12 & 40 & 90\end{array}$

Unlike atropine the effect of scopolamin on the cerebral cortex is to paralyze rather than to irritate, and the frequency of the pulse is not increased but diminished. This has been proved by experiments on animals. It is said to cause no nervous excitability, and not to affect appetite.

'The advantages claimed by Raehlmann for scopolaunin over atropiue are as follows:

(1) Dryness of the throut occurs only after excessive use.

(2) Its application can be prolonged without causing irritation, aud it may even be substituted for atropine when the latter is no longer borne.

(3) It is better adapted to the treatment of cortain inflammatory affections, particularly those connected with hypopyon, than is atropine.

(4) It causes no increase of intraocular pressure, has even been used with relief to pain in cases of acute glaucoma.

If experience corroborates these facts, the new remedy may well supersede atropine. The last ad. vantage cluimed is one of the utmost importance. If we have indeed, in the case of scopolamin, a mydriutic which is unlikely to cause an increase of intraocular pressure, in an eye predisposed to the same, the theory of the action of this class of ageuts must be revised. In that case we must abandon the supposition that excretion is checked by crowding the iris up against the filtration angle, and recur to the former hypothesis that atropive diminishes filtration by contracting the vessels, thus thickening their walls and diminishing transudation.

Raehlmann's article is based on observatious made with scopolamin hydrochlorate. For four weeks past I have used the hydrobromate, the only form of scopolamin I have been able to procure, and which was furnished mo by 'I. Metcalf \& Co. As far as I can judge with so limited an experience the effects are similar. Since commencing with it I have used no atropine.

\section{Olinital @Department.}

\section{REMARKABLE EFFECTS OF DIVULSION OF THE URE'THRA.d \\ BY JOHN HOMANS, M.D. \\ Surycon to the Massachusetts General Hospital.}

IT is very seldom that a surgeon has an opportunity to examine the urethra immediately after divulsion. Such an opportunity has lately been afforded me, and I bring the specimen for the Society to see.

The patient died from the combined effect of hom. orrhage into the cerebellum, hamorrhage into the bowel, tuberculosis of the mesenteric glands, abscesses in the prostate, and the etherization and operation done on the day of his death. The case was an extremely interesting one in every aspect, but more particularly in its pathological appearances.

The patient was a single man, twenty-five years old, who bad led an irregular but very active life for several years, and had taken no care of himself. Some abscesses in the perineum and scrotum had either opened spontaneously or had been opened about a year before his death; and this fact together with a history of gonorrhœa and occasional purulent discharge from the urethra, had given rise to the belief that a tight stricture existed, and that the urethra had ruptured behind it, causing abscesses and sinuses.

When 1 saw the patient early in October, 1893, ho was quite emaciated and very pale. He was extremely unwilling to have any instrument passed, aud it was with the greatest tact that $I$ was ablo to persuade him to let we pass a small one. I tried several, and vearly all of them brought up in false passages, only one went through. Finding these false passages and seeing the sinuses old and healed, only confirmed me in my belief that there was a tight stricture. At the same time the young man said that he had no trouble in passing water, but his attending physician said that urine came at times through the sinuses. In this he was mistaken. 'There was an acquired phymosis with much thickening of the prepuce, and considerable thin pus between the prepuce and the glans. If $I$ could have persuaded the patient to let mo pass a medium-sized instrument, my belief in the existence of any very narrow stricture would have been dispelled.

The patient lived six days after I first saw him. His pulse was always weak, and he developed a most 1 Read before the Boston Socioty for Medioal Improvement, No-
rember 13, 1893. 
intense headache. The pain was terrific, absolutely unbearable, and was accompanied by a spasmodic twitching of both sterno-cleido mastoids. His favorite attitude was with his lands folded behind his head, or with his bead and shoulders bent forward, lying curled up with his back very much rounded.

After etherization, I laid open the sinuses in the scrotum, perineum and buttocks. Two of them were symmetrical and were found to spreal out beneath the skin, as tubercular abscesses do. None of the sinuses communicated with the urechra; they were curetted and packed with iodoform gauze. A small bougio was then passed into the bladder, and the urethra divulsed with Bigelow's divulsor. 'The points of nost resistance were near the glans and in the nembranous portion of the urethra. There was no bleeding. A largesized elastic catheter was easily passed into the bladder, and was tied in and connected by a rubber tube with a bottle. But little urine was secreted after the operation. Eight hours later the patient died. The autopsy showed clearly the cuuses of the pallor, weakness and headache and the effects of the divulsion.

Dr. Whitney reports that the calvaria was thin and its inner ridges and markings extremely prominent, recalling the appearances in the skulls of very old people. In the right hemisphere of the cerebellum was an area of red sofiening occupying the centrul portion for its entire thickness. 'The aroa was rather pyramidal in shape, and its greatest area was about ono inch square. The blood was dark red in color, and was evidently of quite recent origin (probably withiu a week). About six inches above the ileo-cucal valvo was an irregular ulceration, about three-quarters of an inch in diameter, which was well into the muscular coat. The lymphatics were distended with an opaque cheesy material. 'The glands at the root of the mesentery were eularged from the size of a pea to that of an orange, and on section contained abuudant creamy pus with cheesy periphery. The intestine below the ulcer was filled with dark tarry blood. In the prostatic portion of the ureţhra were several holes, capable of admitting a sound, which passed into the prostate and from which yellow pus could bessqueezed. The prostate was completely riddled with abscess formations. 'To sum up : Red softening of the cerebellum; tuberculosis of the mosenteric glands and tubercular ulcer of the intestine; abscesses in the prostate and about the perineum and anus; recent rupture of the urethra from divulsion. Auy other changes in tho viscera, if present, were masked by the fluid injected by the undertaker.

The appeurances of the urethra in the recent state were us follows: At a point two and a half inches from the meatus, and extending two and five-eighths inches downwards, is a clean cut, or tear, parullel witls the axis of the urethra. 'Ilis cut or tear (linear) extends through the mucous wembrane and through tho submucous tissue, un eighth of all inch in depth. In the alcoholic specimen you see at the side of this cut, a shred of membrane (possibly mucous membrane, probably not), but I am not sure that this was there when the autopsy was made; it may have been mado in the slitting open the urethra. In the membranous portion is a clean cut or tear on the floor of the urethra, one inch long and extending to the prostatic urethra, but not into it. The prostatic urethru and the prostate gland are riddled with holes and abscesses of long standing. At first sight this seemed to we rather too extensive a splitting, as the result of the passage of the divulsors, but the more $I$ have studied it and thought about it, the wore I am convinced that it was a most excellent result and could uot have been obtained in any other way. 'There was absolutely no hamorrhage, nor an ecchymosis. The cuts were as straight and clenu as if made by a knifo and not ragged and there was no bleeding as there would have been with a knife. 'There were two strictures, one in the pendulous portion of the urethra, the tightest, and one in the membranous portion. If the urethratome had been used there would have been considerable bleeding and the division of the stricture would have been no more satisfactory, though the incision in the urethra would probably have been shorter.

On the whole, I regard this linear splitting of the urethra, without hamorrhage, almost the ideal treatment for stricture of the ujethra, and if divulsion often effects such a bloodless and thorough division, 1 regard it as perhaps the best method of treating a stricture, at least a deep-seated one.

\section{QESOPHAGOTOMY, WI'TH HEALING BY FIRST IN'TEN'IION.' \\ HY ABNEL POST, M.D.}

'THE following case of ocsophayotomy presents some features of interest, especially in its recovery. The patient was a little girl twelve years of age who on her birthday received as a presont a bright new silver tweuty-five cent piece, which was a larger sum of money than she had had at her own disposal before. In her excitement sho put it in her mouth, and accidentally swallowed it. For the first day after the accident she was unable to swallow anything. On the second day the coin evidently shifted, and she was able to swallow liquids. At the end of tho second day she was brought to the hospital. I saw her late the next forenoon. She was evidently in pain; and when I approached her, she screaned, and grasped her throat by both hands. It was impossiblo even to touch her without anasthesia, and the next day was appointed for the operation. 'T'he next morning she persuaded her nurse that sho was ablo to swallow, that the coin had passed down; and I was so informed, so that I did uot see her (ill late that forenoon, when I asked to see her swallow. Sho took but a single swallow, grabbed the throat with both hands, and made that characteristic painful deglutition which is so well-known with difficulty in the osophagus. I was obliged again to postpoue the operation until the next day, which was the fitch since she swallowed the coin.

When she was etherized an attempt was made with the coin-catcher to catch and extract the coin. I succeeded in locating it, but did not catch the coin. The bristle probang was then pussed; it came up showing that the bristles had spread irregularly, and that the portion of the probang where the bristles had been thinnest had caught in the coin. The instrument was passed again, but no force that 1 dared apply would stir the coin. The probang came up with a littlo blood, and it was evident that csophagotomy was necessary. 'The child being already on the table, the head turned to the right exposing the loft side, which was mado prominent by placing a rolled sheet beneath the 1 Ilend boforo the Boston Socioty for Medical Improvement, No1 Irend boforo
vombor 13,1803 . 